\title{
Extracerebral Pterional Metastasis from Malignant Meningioma: A Case Report
}

\section{Metástase pterional extracerebral de meningioma maligno: Relato de caso}

\author{
Edmundo Luís Rodrigues Pereira ${ }^{1}$ Diego Arthur Castro Cabral ${ }^{2(1)}$ Fernanda Myllena Sousa Campos ${ }^{20}$ \\ ${ }^{1}$ Department of Neurosurgery, Universidade Federal do Pará, Guamá, \\ Belém, PA, Brazil \\ 2 Instituto de Ciências da Saúde, Faculdade de Medicina, Universidade \\ Address for correspondence Diego Arthur Castro Cabral, Faculdade \\ de Medicina, Universidade Federal do Pará, Guamá, Belém - PA, 66075- \\ 110, Brazil (e-mail: diego.arthur.castro@gmail.com).
} Federal do Pará, Guamá, Belém, PA, Brazil

Arq Bras Neurocir 2021;40(2):e174-e178.

\begin{abstract}
Keywords

- atypical meningioma

- malignant meningioma

- metastasis

Resumo

\section{Palavras-chave}

- meningioma atípico

- meningioma maligno

- metástase

Anaplastic or malignant meningiomas that are classified as World Health Organization (WHO) grade III account for less than $1 \%$ of all meningiomas diagnosed. Despite the aggressive course, distant metastases are a rarity, occurring in only $0.1 \%$ to $0.2 \%$ of cases. We report the case of a 56-year-old woman who presented with parasagittal benign meningioma that underwent malignant transformation along with metastasis into the right orbitosphenoid region. The clinical, radiological, and histopathological aspects are highlighted, with an emphasis on the natural history of meningiomas.

Meningiomas anaplásicos ou malignos classificados como grau III da Organização Mundial da Saúde (OMS) representam menos de 1\% de todos os meningiomas diagnosticados. Apesar do curso agressivo, as metástases à distância são raras, ocorrendo em apenas $0,1 \%$ a $0,2 \%$ dos casos. Relatamos o caso de uma mulher de 56 anos que apresentou meningioma benigno parassagital que sofreu transformação maligna e metástase para a região orbito esfenoidal direita. São destacados os aspectos clínicos, radiológicos e histopatológicos, com destaque para a história natural dos meningiomas.
\end{abstract}

\section{Introduction}

Meningiomas are primary neoplasms that affect the central nervous system (CNS) of adults and can be found wherever there is arachnoid membrane. They have an estimated incidence of 4 to 6 cases per 100,000 people per year, and an approximate prevalence of 97.5 per 100,000 inhabitants in the United States. ${ }^{1,2}$ They are classified by the World Health
Organization (WHO) according to tumor differentiation and mitotic activity into 3 types: benign (WHO grade I), atypical (WHO grade II), and anaplastic or malignant (WHO grade III). ${ }^{3}$ Most cases are of the first type, often resulting from deletions in chromosome 22q12, leading to the inactivation of the neurofibromin 2 (NF2) gene, which is also called merlin or schwannomin. This is clinically manifested by a long-term oligosymptomatic course and uniform histology that is devoid received

July 9,2020

accepted

November 16, 2020

published online

February 15, 2021
DOI https://doi.org/ $10.1055 / \mathrm{s}-0040-1722247$ ISSN $0103-5355$.

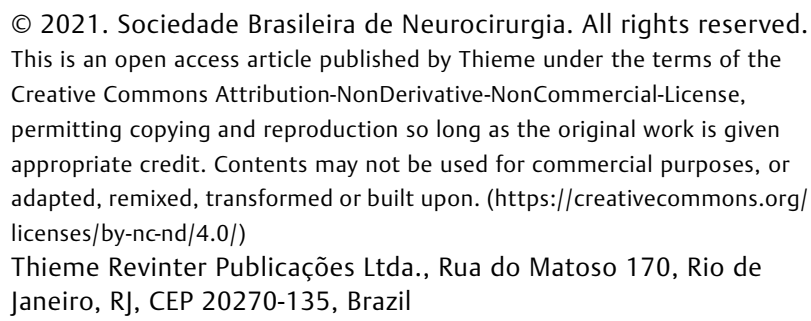


of atypia and mitosis, respecting the limits of the neuropil. The other two less common types of meningioma are associated with a mosaic of chromosomal losses at 1p, 6q, 10 and 14q, and amplification at 17q23. This results in polymorphic histology: atypia, mitoses, and a more aggressive behavior affecting the neurovascular structures and invasion of nervous tissue., ${ }^{4,5}$ Similar to astrocytomas, the malignant forms (grade III) may be primary ('de novo'), when they appear with this phenotype, or secondary, when they result from transformation of a lower histological grade meningioma. Regardless of their origin,
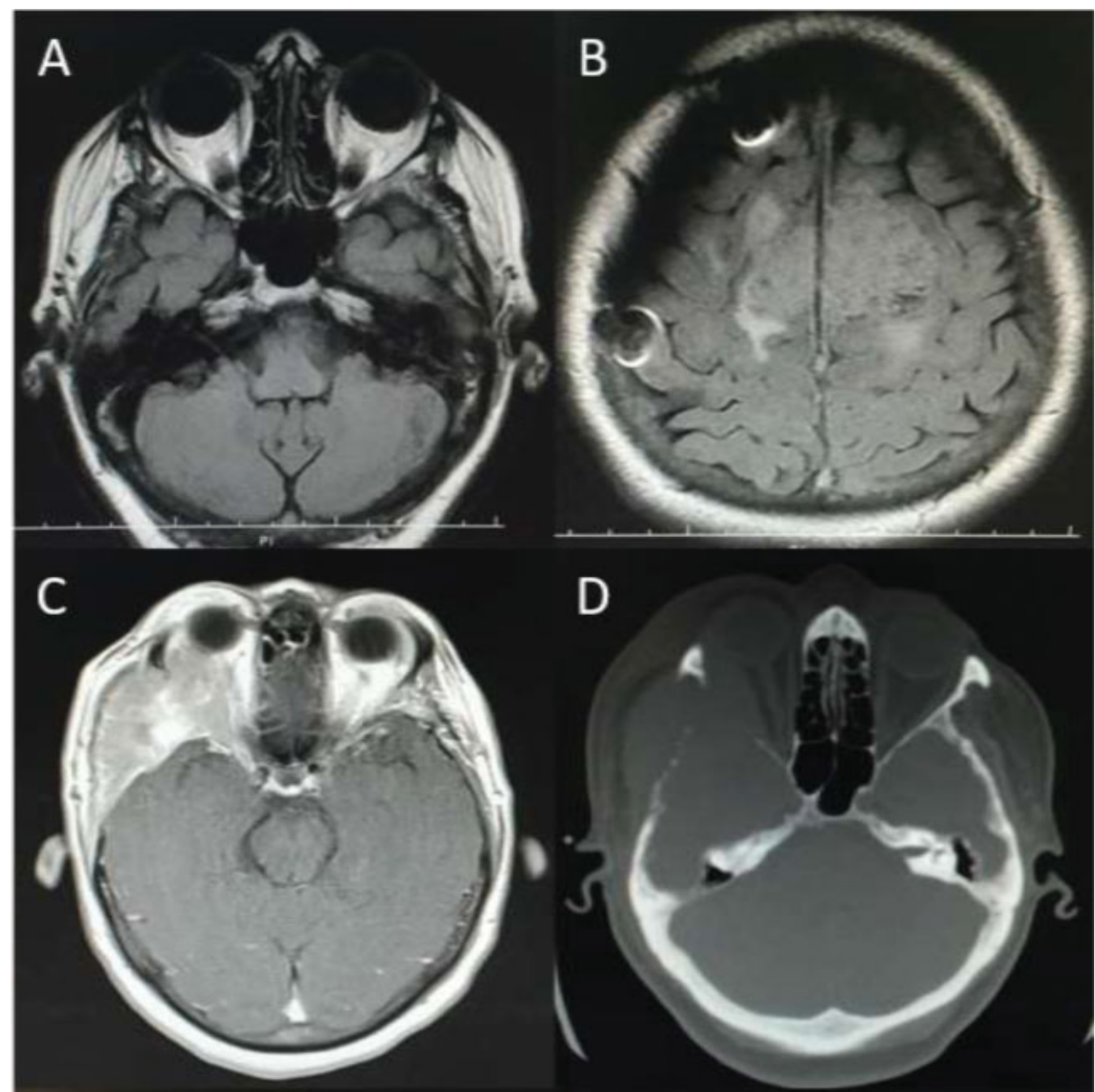

D
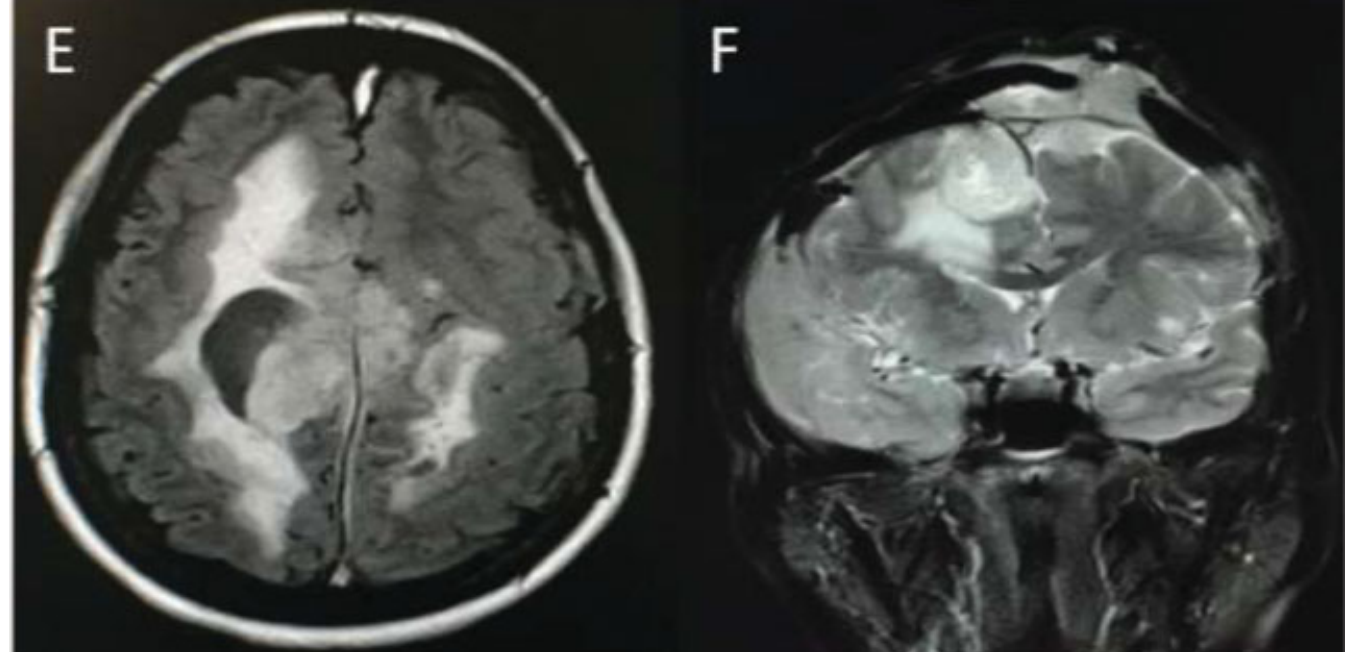

Fig. 1 Magnetic resonance imaging (MRI) scan 8 months after the first surgery (2012) (A, B). In 2015, the patient underwent an MRI scan that showed a large orbitotemporal mass (C) and a computed tomography (CT) scan of the skull with temporal osteolysis (D). Magnetic resonance imaging scan of the skull demonstrating cystic solid neoplasia with edema and sagittal sinus invasion (E,F). Radiological findings indicate the malignant transformation that the tumor underwent (C-F). 
grade-III meningiomas always indicate a very severe disease, with recurrence rates close to $95 \%$, and an average survival limited to 1.5 years. ${ }^{6,7}$ This adverse scenario results from the difficulty of performing total exeresis of these tumors due to infiltration of eloquent structures and invasion of neural tissue combined with very high cell proliferation kinetics. ${ }^{8,9}$ With regard to the treatment of this class of tumors, surgical resection continues to be the best option in most cases in which the clinical condition and characteristics of the neoplasm enable an operative intervention, followed by adjuvant radiotherapy. To date, there is controversy about the efficacy of chemotherapeutic agents with conflicting results; therefore, this method is not used routinely. ${ }^{10}$

\section{Case Report}

JAS, a 56-year-old woman, began to suffer from generalized seizures in 2012, and was diagnosed with an expansive lesion in the bilateral frontal (parasagittal) region, which was larger on the right side. The patient underwent surgical treatment due to the involvement of cortical veins and the partially patent superior sagittal sinus. The only treatment to which the patient was submitted was surgery; she did not undergo any other treatments, such as chemotherapy and/or radiotherapy. Partial resection of the neoplasm (Simpson 3) was chosen, with the histopathology confirming that it was fibroblastic meningioma of WHO grade I. The patient was followed up on a regular basis, periodically underwent magnetic resonance imaging scans, showed apparent residual disease stability, and asymptomatic clinical course until July 2015. At this point, she started complaining of right retroocular pain, accompanied by ophthalmoplegia and low visual acuity on the same side (-Fig. 1). In the following weeks, the lesion became apparent under the skin of the right orbital and temporal areas. There was an increase in volume of the frontal region surrounding the previously-operated site, gradual worsening, and episodes of seizures accompanied by sensory alteration. The imaging showed a large expansive lesion occupying the right pterional region, with extensive osteolysis of the temporal bone, zygoma, and orbital wall (-Fig. 1). There was also a significant change in the shape and volume of the frontal residual mass, which had multilobulation, signs of invasion of subcutaneous tissue and the superior sagittal sinus, formation of cystic cavity, and perilesional edema. Due to the systemic (Karnofsky 30) and neurological (Glasgow 11) involvement, we chose to perform diagnostic macrobiopsy (Simpson 5). The histopathological analysis confirmed the progression of the initial tumor to a WHO grade-III malignant meningioma with highly positive immunohistochemistry for epithelial membrane antigen (EMA), weakly positive for progesterone receptor, and high proliferative index ( $\mathrm{K}_{\mathrm{i}}-67$ expression; $20 \%$ to $30 \%$ ) (-Fig. 2). Two weeks after the biopsy, the patient succumbed to the disease.

\section{Discussion}

About $90 \%$ of the meningiomas diagnosed in the clinical practice correspond to the benign form (WHO grade I). The remaining are atypical meningiomas (WHO grade II), which account for $5 \%$ to $7 \%$ of the cases, and malignant meningiomas (WHO grade III), which are rare, appearing in less than $3 \%$ of patients. ${ }^{11,12}$ In prognostic terms, almost $80 \%$ of the patients with benign meningiomas survive for 10 years after the diagnosis, while only $40 \%$ of people with malignant meningiomas survive the disease for a decade, corresponding to a 5-year mortality rate of $70 \%{ }^{13,14}$

Metastasis is one of the classic signs of aggressiveness and malignancy in a neoplasm, ${ }^{15,16}$ so it is logical to expect the tumor to spread almost exclusively in cases of atypical and anaplastic meningiomas. However, there are several reports on the occurrence of metastasis in benign meningiomas (WHO grade I). ${ }^{17,18}$ A recent systematic review ${ }^{19}$ of distant metastasis of meningiomas published in 2013 identified only 115 cases; $34 \%$ of them originated from benign meningiomas, while the remainder were atypical (21\%) and malignant (40\%) meningiomas, most often appearing almost five years after the first surgery.

It is likely that the intriguing proportion observed among the three groups, in which a surprisingly high number of metastasis from benign meningiomas is noted, may express an analytical or aggregation bias, since most (90\%) cases diagnosed in the clinical practice are of WHO grade I on the histological examination. However, considering that this retrospective study ${ }^{19}$ included histological criteria prior to the current WHO classification of CNS tumors, ${ }^{3}$ in addition to the existence of a somewhat poorly -defined class of benign meningiomas containing atypias, ${ }^{20}$ the high number of metastases found in 'benign' meningiomas warns that this complication is not negligible. It occurs more often than expected, leading to the need to reassess the more conservative management in these cases. ${ }^{21}$

In the case presented here, it appears that the metastasis came from the parasagittal tumor, originally a WHO grade-I fibroblastic meningioma, which progressed to malignant transformation, rapidly increasing in volume with the invasion of local structures, particularly cortical veins tributary to the superior sagittal sinus. Since intracranial veins are devoid of valves, ${ }^{22}$ it is likely that invasion/occlusion of the superior sagittal sinus caused a reversal in centrifugal venous drainage from the cerebral cortex to the jugular veins. This led to the direction of the blood flow to the venous group through the great anastomotic Trolard vein or even the Labbe vein, a possible way in which metastasis could reach the pterional region from the frontal region. ${ }^{23}$

Unlike the original benign tissue, devoid of atypia or signs of anaplasia, the tumor sample collected from the progression/metastasis stage revealed several signs of atypia, such as increased cell population, prominent nucleoli, cell stratification, and altered nucleus-cytoplasm relationship, with foci of mitosis. Such morphological features were further complemented by immunohistochemistry, which not only confirmed the meningeal nature of the neoplasm (staining the cells strongly by the epithelial membrane antigen, poor progesterone receptor labeling, cytokeratin negativity), but also marked proliferative kinetics expressed by a high proliferative index ( $\mathrm{K}_{\mathrm{i}}-67$ expression), quantified between $20 \%$ and $30 \%{ }^{24}$ 


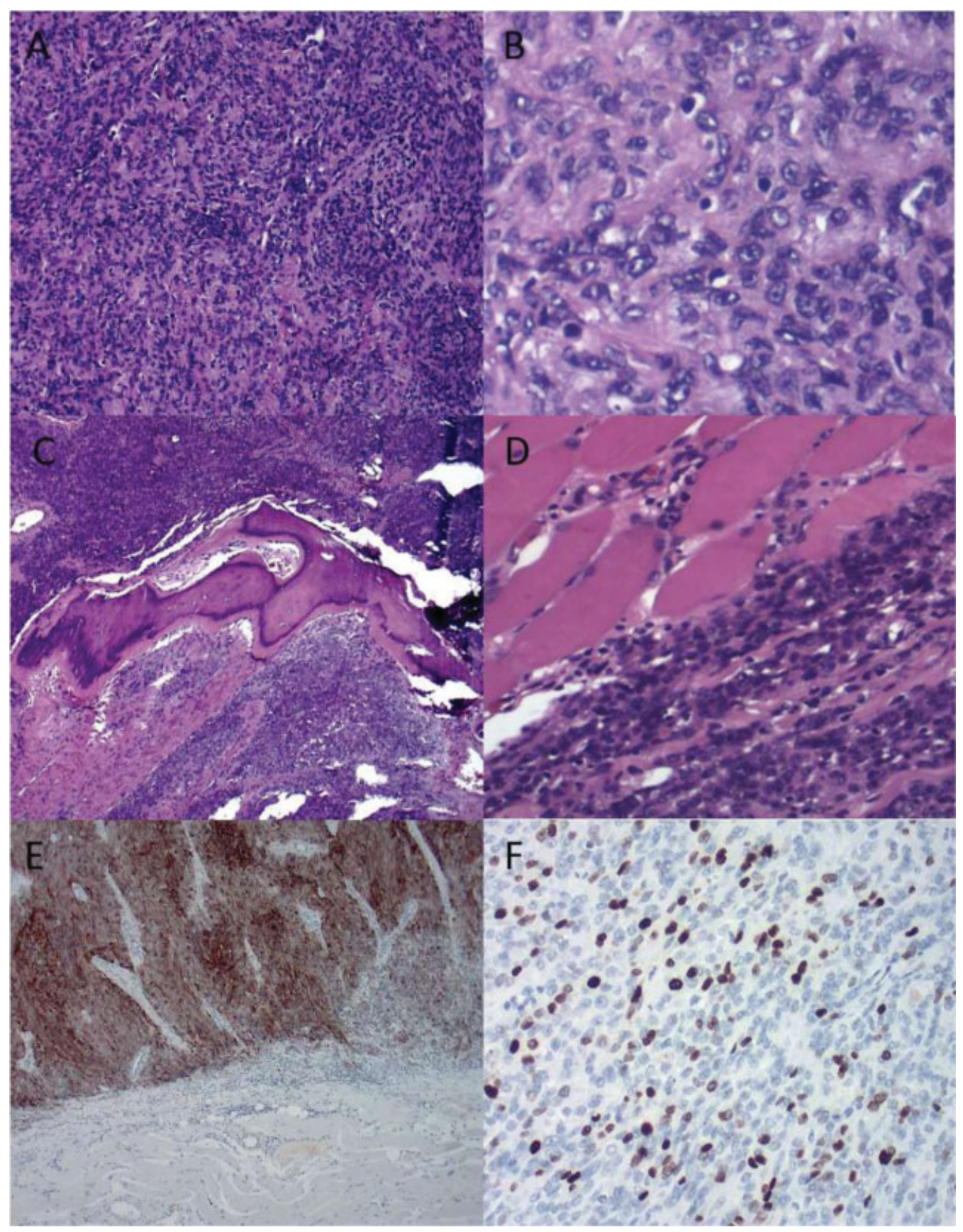

Fig. 2 (A,B) Cellular polymorphism with atypias and mitoses. (C) Bone infiltration. (D) Invasion of the temporal muscle. (E,F) Histopathological examination with positive result for epithelial membrane antigen (EMA) and high $\mathrm{K}_{\mathrm{i}}-67$ (20-30\%) expression respectively.

Finally, the transformation of a benign meningioma into a malignant meningioma raises the question of whether this process could be part of the natural history of meningiomas in general; does a grade-I benign form gradually evolve to the grade-III malignant type through an intermediary grade-II atypical stage, as seen in secondary glioblastomas, or does it merely 'jump' directly, from benign to malignant grade III, without any intermediary stage? In any case, perhaps it will be more reasonable to adopt a less conservative approach when facing benign meningiomas.

\section{Conclusion}

Metastasis of meningiomas are rarely seen in the neurological practice. When they occur, they represent an additional problem that indicates a poor prognosis that may progress rapidly, as in the case presented here, to an advanced and fatal disease. The evolution from a typical or atypical meningioma to a malignant meningioma is an important aspect of the report herein presented, as it warns of this possibility in the natural history of the disease. This suggests that some of these low-grade lesions are 
only an evolutionary stage, and that by mechanisms not yet fully understood they may develop malignancy. The possibility of malignancy of benign meningiomas confirms the general idea that the surgical treatment should aim, whenever possible, for the complete removal of all meningeal tumor with safety margins, as provided in Grade I of the Simpson classification. ${ }^{25}$

\section{Conflict of Interests}

The authors have no conflict of interests to declare.

\section{References}

1 Ostrom QT, Gittleman H, Liao P, Vecchione-Koval T, Wolinsky Y, Kruchko C, Barnholtz-Sloan JS. CBTRUS Statistical Report: Primary brain and other central nervous system tumors diagnosed in the United States in 2010-2014. Neuro-oncol 2017;19(Suppl 5):v1-v88

2 Claus EB, Bondy ML, Schildkraut JM, Wiemels JL, Wrensch M, Black PM. Epidemiology of intracranial meningioma. Neurosurgery 2005;57(06):1088-1095, discussion 1088-1095

3 Louis DN, Perry A, Reifenberger G, et al. The 2016 World Health Organization classification of tumors of the central nervous system: a summary. Acta Neuropathol 2016;131(06):803-820

4 Galani V, Lampri E, Varouktsi A, Alexiou G, Mitselou A, Kyritsis AP. Genetic and epigenetic alterations in meningiomas. Clin Neurol Neurosurg 2017;158:119-125

5 Cimino PJ. Malignant progression to anaplastic meningioma: Neuropathology, molecular pathology, and experimental models. Exp Mol Pathol 2015;99(02):354-359

6 Wang J, Wang L, Luo B, et al. Recurrent meningioma with malignant transformation: a case report and literature review. Int J Clin Exp Med 2015;8(09):16845-16849

7 Hortobágyi T, Bencze J, Varkoly G, Kouhsari MC, Klekner Á Meningioma recurrence. Open Med (Wars) 2016;11(01):168-173

8 Graffeo CS, Leeper HE, Perry A, et al. Revisiting Adjuvant Radiotherapy After Gross Total Resection of World Health Organization Grade II Meningioma. World Neurosurg 2017;103:655-663

9 Hasan S, Young M, Albert T, et al. The role of adjuvant radiotherapy after gross total resection of atypical meningiomas. World Neurosurg 2015;83(05):808-815

10 Sun SQ, Hawasli AH, Huang J, Chicoine MR, Kim AH. An evidencebased treatment algorithm for the management of WHO Grade II and III meningiomas. Neurosurg Focus 2015;38(03):E3

11 Rogers L, Barani I, Chamberlain M, et al. Meningiomas: knowledge base, treatment outcomes, and uncertainties. A RANO review. J Neurosurg 2015;122(01):4-23
12 Asioli S, Senetta R, Maldi E, et al. "Benign" metastatic meningioma: clinico-pathological analysis of one case metastasising to the lung and overview on the concepts of either primitive or metastatic meningiomas of the lung. Virchows Arch 2007;450 (05):591-594

13 Sughrue ME, Sanai N, Shangari G, Parsa AT, Berger MS, McDermott MW. Outcome and survival following primary and repeat surgery for World Health Organization Grade III meningiomas. J Neurosurg 2010;113(02):202-209

14 Sanai N, Sughrue ME, Shangari G, Chung K, Berger MS, McDermott MW. Risk profile associated with convexity meningioma resection in the modern neurosurgical era. J Neurosurg 2010;112(05): 913-919

15 Fouad YA, Aanei C. Revisiting the hallmarks of cancer. Am J Cancer Res 2017;7(05):1016-1036

16 Hanahan D, Weinberg RA. The hallmarks of cancer. Cell 2000;100 (01):57-70

17 Satoh YY Satoh. , Ishikawa YY Ishikawa. . Multiple primary pulmonary meningiomas: 20 -year follow-up findings for a first reported case confirming a benign biological nature. Int J Surg Case Rep 2017;31:58-60

18 Cho BR, Yoon WS. Pulmonary metastases from benign calvarial meningioma: a case report. $\mathrm{Br}$ J Neurosurg 2017;31(02): 276-278

19 Surov A, Gottschling S, Bolz J, et al. Distant metastases in meningioma: an underestimated problem. J Neurooncol 2013;112(03): 323-327

20 Marciscano AE, Stemmer-Rachamimov AO, Niemierko A, et al. Benign meningiomas (WHO Grade I) with atypical histological features: correlation of histopathological features with clinical outcomes. J Neurosurg 2016;124(01):106-114

21 Kanthan R, Senger JL. Distant metastases from meningiomas-A myth or reality? Ann Clin Pathol 2013;1(01):1001

22 Egemen E, Solaroglu I. Anatomy of Cerebral Veins and Dural Sinuses. In: Primer on Cerebrovascular Diseases. 2nd ed. 2017: 32-36

23 Adachi K, Hasegawa M, Hirose Y. Evaluation of Venous Drainage Patterns for Skull Base Meningioma Surgery. Neurol Med Chir (Tokyo) 2017;57(10):505-512

24 Pavelin S, Becic K, Forempoher G, et al. Expression of ki-67 and p53 in meningiomas. Neoplasma 2013;60(05):480-485https:// www.researchgate.net/publication/241690536_Expression_of_Ki-67_and_p53_in_meningiomas

25 Heald JB, Carroll TA, Mair RJ. Simpson grade: an opportunity to reassess the need for complete resection of meningiomas. Acta Neurochir (Wien) 2014;156(02):383-388 